\title{
CONDITIONS FOR THE PRODUCTION OF ESCHERICHIA COLI ENTEROTOXIN IN A DEFINED MEDIUM
}

\author{
I. DE G. Mitchell, M. J. TAMe AND R. Kenworthy \\ Unilever Research Laboratory, Colworth House, Sharnbrook, Bedfordshire
}

CONFUSION exists about the chemical and physico-chemical characteristics of enterotoxins produced in culture supernates by strains of Escherichia coli pathogenic for pigs and reported upon by Smith and Halls (1967), Kohler (1968), Larivière (1971), and Bywater (1972). We considered that some of the apparent anomalies might be attributed to the presence of peptides and polypeptides in the media used for bacterial growth, namely "syncase" medium (Finkelstein, Norris and Dutta, 1964; Kohler, 1968) and semisolid nutrient agar (Smith and Halls, 1967). This paper describes the development of a defined medium based on mineral salts, glucose and vitamins, and compares the characteristics of the enterotoxic supernates from growth in this medium with those yielded by growth in " syncase " medium.

\section{MATERIALS AND METHODS}

Strains of Escherichia coli. Strains P6 (serotype O?; K?; H16), P99 (O141; K85; K88a, b; H4) and P16 (09; K9) were obtained from Dr H. W. Smith (Houghton Poultry Research Station, Houghton, Huntingdonshire) and strain K12 from the National Collection of Industrial Bacteria (no. NCIB9482). Strains P99 and P16 produce enterotoxin and cause diarrhoea in pigs (Smith and Halls, 1967), whereas the porcine strain P6 and the laboratory strain K12 do not.

Media. A defined medium, which will be described under Results, and various modifications of it, were used in studies of the optimum conditions for enterotoxin production. For comparison cultures were grown in " syncase" medium (Finkelstein et al., 1964; Kohler, 1968 ) and tested similarly. The composition of "syncase " medium (percentage $w / v$ ) was $\mathrm{Na}_{2} \mathrm{HPO}_{4} 0.5, \mathrm{~K}_{2} \mathrm{HPO}_{4} 0.5$, sucrose 0.5, $\mathrm{NH}_{4} \mathrm{Cl} 0.118, \mathrm{Na}_{2} \mathrm{SO}_{4} 0.0089, \mathrm{MgCl}_{2} \cdot 6 \mathrm{H}_{2} \mathrm{O}$ $0.0042, \mathrm{MnCl}_{2} \cdot 4 \mathrm{H}_{2} \mathrm{O} 0.0004, \mathrm{FeCl}_{2} \cdot 6 \mathrm{H}_{2} \mathrm{O} 0.0005$, acid-hydrolysed casein 1.0.

Assay of enterotoxin. The activity of supernates was measured in ligated segments (loops) of porcine intestine by the method of Smith and Gyles (1970), derived from those of De and Chatterjee (1953) and Moon, Sorensen and Sautter (1966). The loop volume (ml of fluid per $\mathrm{cm}$ length) for the test sample was divided by the loop volume for a "standard toxin" prepared by 24-hour growth of strain P16 in " syncase " medium. Thus a comparison could be made of samples in different pigs. Samples in inactive regions of intestine were disregarded, but even so the results in this assay varied by as much as $\pm 25 \%$ for the same sample. All samples were tested once in at least two and usually four different pigs. Pigs were 21 days old when used and had been weaned on the previous day and starved for 24 hours.

Gel filtration. Supernates of cultures in " syncase" medium and in the defined medium that had similar enterotoxic activities in ligated intestine were freeze-dried and reconstituted in distilled water to give 15-fold concentration. These were then passed through SephadexG50 columns with $0.85 \% \mathrm{NaCl}$ eluant. Sephadex-G50 was obtained from Pharmacia Fine Chemicals, Uppsala, Sweden, and the results were expressed in KAV units calculated as follows.

$$
\mathrm{KAV}=\frac{V e-V o}{V t-V o}
$$

where $V e=$ elution volume, $V t=$ bed volume, and $V o=$ void volume. The column effluent 
was monitored for optical transmission at $280 \mathrm{~nm}$ on a Uvicord II apparatus made by L.K.B., Ltd., Bromma, Sweden.

\section{RESULTS}

Final composition of the medium

All quantities are given as percentages (w/v) except where otherwise stated. The medium contained glucose 1.0, $\mathrm{Na}_{2} \mathrm{HPO}_{4} \mathbf{0 . 5}, \mathrm{K}_{2} \mathrm{HPO}_{4} \quad 0.5, \mathrm{MgSO}_{4} \cdot 7 \mathrm{H}_{2} \mathrm{O} 0.02, \mathrm{CaCl}_{2} \mathbf{0 . 0 0 5}$, $\left(\mathrm{NH}_{4}\right)_{2} \mathrm{SO}_{4} 0.2$, vitamin solution $0.1(\mathrm{v} / \mathrm{v})$, trace solution $0.1(\mathrm{v} / \mathrm{v})$. The vitamin solution contained meso-inositol $0 \cdot 5$, thiamine $0 \cdot 1$, nicotinic acid $0 \cdot 1$, riboflavin $0 \cdot 1$, calcium pantothenate $0.1, p$-amino-benzoic acid 0.05 , pyridoxin $0 \cdot 1$, biotin 0.0005 ; the trace solution contained $\mathrm{MnSO}_{4} \cdot 4 \mathrm{H}_{2} \mathrm{O} 0.05, \mathrm{Fe}\left(\mathrm{NH}_{4}\right)_{2} \mathrm{SO}_{4} \cdot 6 \mathrm{H}_{2} \mathrm{O} 0.5, \mathrm{ZnSO}_{4} \cdot 7 \mathrm{H}_{2} \mathrm{O} 0 \cdot 4, \mathrm{CuSO}_{4} \cdot 5 \mathrm{H}_{2} \mathrm{O}$ $0.05, \mathrm{Co}\left(\mathrm{NO}_{3}\right)_{2} \cdot 6 \mathrm{H}_{2} \mathrm{O} 0.05, \mathrm{KI} 0.05, \mathrm{H}_{3} \mathrm{BO}_{3} 0.05, \mathrm{NaMoO}_{4} \cdot 6 \mathrm{H}_{2} \mathrm{O} 0.05$.

\section{TABLE}

Yield of enterotoxin from strains $P 16$ and $P 99$ when grown in the defined medium with the $\mathrm{pH}$ controlled at $\mathbf{7 \cdot 7}$

\begin{tabular}{|c|c|c|c|c|c|}
\hline \multirow{2}{*}{$\begin{array}{l}\text { Strain } \\
\text { number }\end{array}$} & \multirow{2}{*}{$\begin{array}{l}\text { Duration of } \\
\text { incubation } \\
\text { (hours) }\end{array}$} & \multirow{2}{*}{$\begin{array}{l}\text { Total count } \\
\left(\times 10^{-9} \text { per ml }\right)\end{array}$} & \multicolumn{2}{|c|}{ Number of } & \multirow{2}{*}{$\begin{array}{c}\text { Average } \\
\text { enterotoxic } \\
\text { activity } \dagger\end{array}$} \\
\hline & & & $\begin{array}{l}\text { separate } \\
\text { experiments }\end{array}$ & $\begin{array}{l}\text { assays per } \\
\text { experiment }\end{array}$ & \\
\hline P16 & $\begin{array}{l}24 \\
48 \\
72\end{array}$ & $\begin{array}{r}3.4 \\
11.0 \\
\ldots\end{array}$ & $\begin{array}{l}1 \\
2 \\
1\end{array}$ & $\begin{array}{l}2 \\
2 \\
2\end{array}$ & $\begin{array}{l}0.2 \\
0.8 \\
1.0\end{array}$ \\
\hline P99 & $\begin{array}{l}24 \\
48 \\
72\end{array}$ & $\begin{array}{l}4.8 \\
7.1 \\
7.9\end{array}$ & $\begin{array}{l}1 \\
2 \\
1\end{array}$ & $\begin{array}{l}2 \\
2 \\
2\end{array}$ & $\begin{array}{r}<0.1 \\
0.2 \\
0.3\end{array}$ \\
\hline
\end{tabular}

$\ldots=$ Not done.

* By Thoma haemocytometer.

† Loop volume (ml per $\mathrm{cm}$ of gut) for test sample/" standard" toxin.

\section{Optimal conditions for enterotoxin production in the defined medium}

The inoculum $(100 \mathrm{ml})$ was prepared by growing strain P16 or strain P99 in the defined medium, aerated, at $37^{\circ} \mathrm{C}$ for 24 hours. This was used to seed 1.01 of the defined medium, which was then incubated at $37^{\circ} \mathrm{C}$ for 48 or 72 hours in a 3-1 flask shaken at 90-100 cycles of $3.75 \mathrm{~cm}$ amplitude per min. The $p \mathrm{H}$ was controlled at a mean of between 7.5 and 8.0 and not allowed to fluctuate by more than \pm 0.75 units.

When grown under these conditions strain P16 yielded nearly as much enterotoxin as when grown in "syncase" medium though the yield from strain P99 was somewhat less (the table).

\section{Effect of variations in composition of the defined medium and in growth conditions}

Concentration of glucose. The presence of $1 \%$ glucose in the defined medium resulted in marginally more enterotixic activity than did $0.5 \%$ and significantly more than did $0.25 \%$, but slime in the supernate increased markedly with increase in glucose concentration.

Source of nitrogen. Various ammonium salts, urea, asparagine and arginine were tested individually without $p \mathrm{H}$ control; little enterotoxin was produced. However, if the $p \mathrm{H}$ was controlled at 7.7 , medium containing 0.2 or $0.1 \%$ of ammonium sulphate gave levels of enterotoxic activity similar to those obtained in " syncase" medium. 
Concentration of phosphate. Reduction of the concentration of phosphate to half that used in the final medium significantly reduced yields of enterotoxin.

Vitamins. Growth did not occur in the absence of the vitamin solution. Occasionally the use of an "old" vitamin solution permitted normal growth but gave very low yields of enterotoxin. This suggests that there might be a requirement for an unstable vitamin for synthesis of toxin.

$p \mathrm{H}$ during growth. When the $p \mathrm{H}$ was not controlled, the $p \mathrm{H}$ profiles during growth in " syncase" medium and in the defined medium differed considerably (fig. 1). The drop in $p \mathrm{H}$ in the defined medium occurred mainly during the log phase and about $130 \mathrm{ml}$ of $1-\mathrm{N}$ $\mathrm{NaOH}$ per 1 had to be added to prevent its occurrence. Enterotoxic activity was tested for

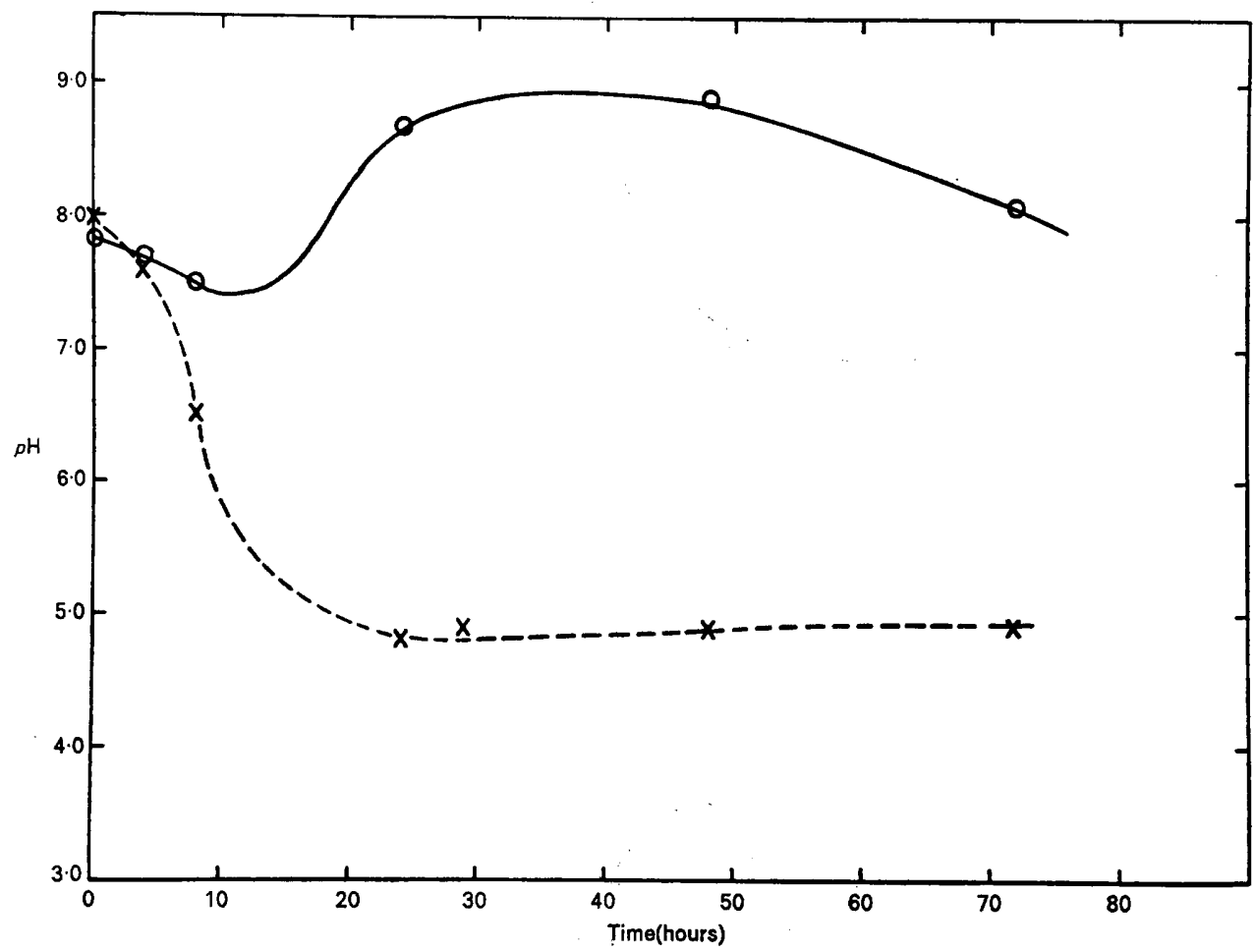

FIG. 1.-Changes in $p \mathrm{H}$ during growth of Escherichia coli strain P99 in the defined medium $(x--x)$ and in "syncase " medium $(\mathrm{O} \longrightarrow \mathrm{O})$ at $37^{\circ} \mathrm{C}$.

in the defined medium when the $p \mathrm{H}$ was either uncontrolled or controlled at $6 \cdot 7,7 \cdot 2,7 \cdot 4$, $7 \cdot 7,7 \cdot 9,8 \cdot 1$ and $8 \cdot 3$ (fig. 2). In the " controlled" experiments it was not allowed to fluctuate by more than \pm 0.75 units except during the lag phase, when a fall to 7.0 was permitted to encourage an early onset of logarithmic growth. Generally the $p \mathrm{H}$ during the first 24 hours should be slightly below the required mean to compensate for a small rise during the subsequent 24 hours if alkali or acid is not added during this period. When the $p \mathrm{H}$ is controlled between 7.4 and $8 \cdot 1$, yields of enterotoxin similar to those obtained in "syncase " medium can be achieved (fig. 2). However, when the $p \mathrm{H}$ exceeded 8.0 difficulty was experienced in initiating growth of strain P16.

It was observed that neither strain P16 grown in defined medium (fig. 2) nor strain P99 grown in "syncase" medium produced much enterotoxin below $p \mathrm{H} 6.5$. Not only was significant production of enterotoxin confined to $\mathrm{pH}$ values exceeding 7.0 but also both of the pathogenic strains, P16 and P99, grew markedly better in the defined medium at $p \mathrm{H}$ values above 7.5 than did the non-pathogenic strains P6 and K12. 


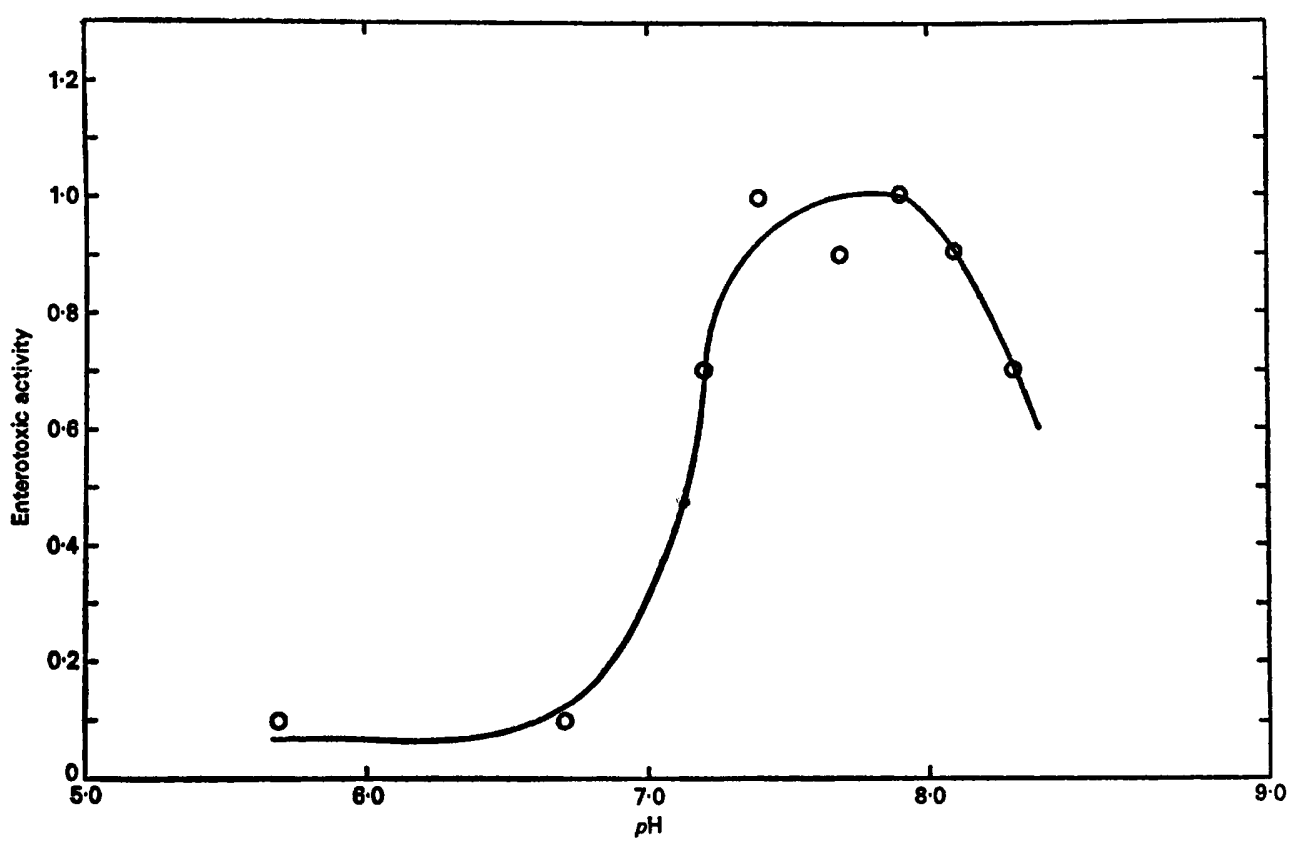

Fia. 2.-Effect of mean $p \mathrm{H}$ on enterotoxin production in shaken cultures of Escherichia coli strain P16 in the defined medium. (For definition of enterotoxic activity see text.)

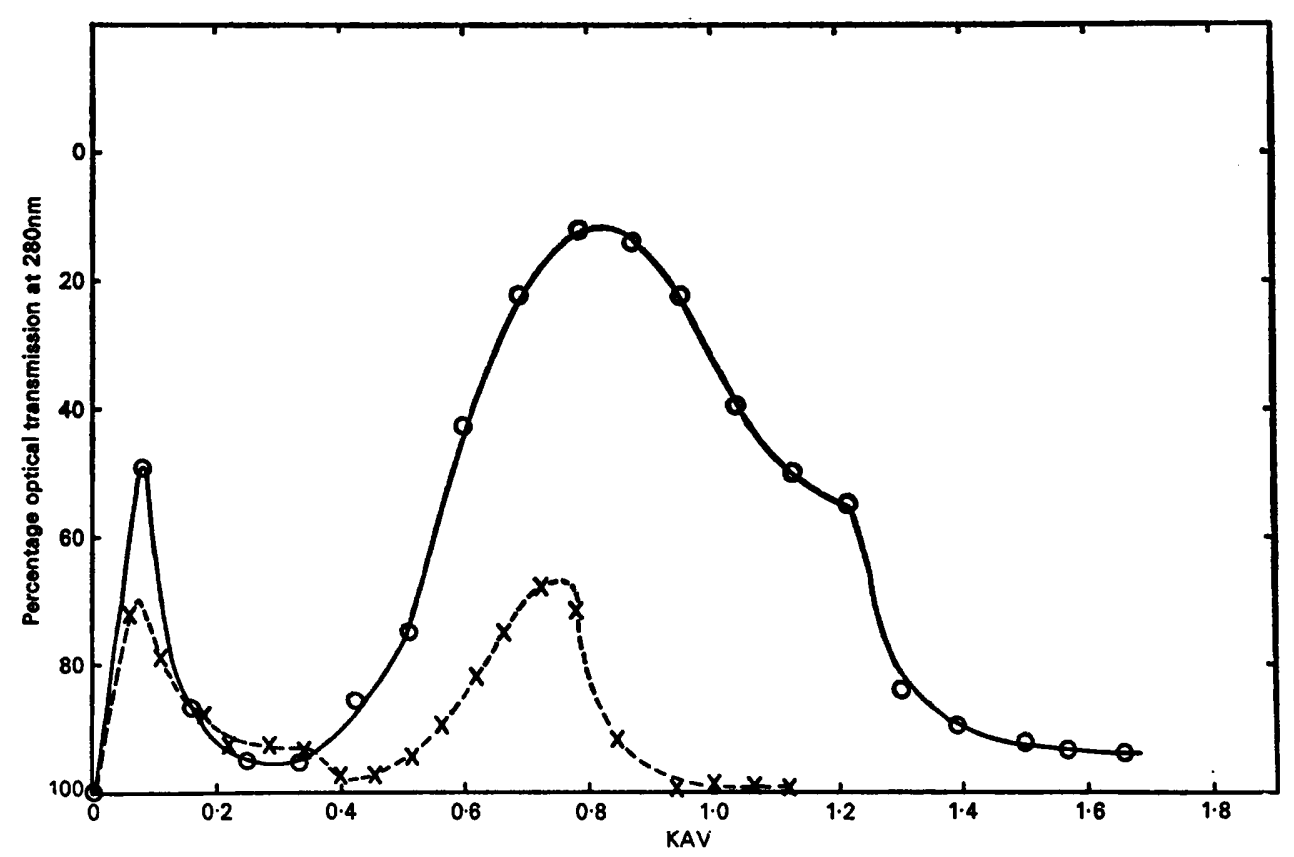

FIG. 3.-Ultraviolet-light absorbence of fractions (KAV; see text) obtained by filtration of culture supernates of Escherichia coli strain P16 through Sephadex G.50; $x---x=$ supernate from the defined medium; $O-O$ supernate from "syncase "medium. 
Aeration. In unshaken cultures in both " syncase" medium and the defined medium ( 1.01 of medium in a 3-1 flask), the yields of enterotoxin were insignificant; if the cultures were shaken, however, good yields were obtained in both media. Yields were increased marginally if a 5-1 flask was used with the same volume of medium.

Duration of incubation. Very little enterotoxin was produced in defined medium after 24 hours' incubation, but in " syncase" medium the yields were nearly maximal in this period; maximum yields were obtained after 48 hours in defined medium (the table).

Preparation and size of inoculum. For toxin production in the defined medium it was best to prepare inocula also in defined media. If inocula were prepared in other media, e.g., " syncase" or nutrient broth, a very long lag phase ensued, presumably because the bacteria needed to adapt to the defined medium. An inoculum of $10 \%(\mathrm{v} / \mathrm{v})$ gave a much shorter lag phase than did one of $1 \%$ but there was no significant difference in final yield of enterotoxin.

\section{Ultraviolet (UV)-light absorbence of effluents after gel filtration}

Supernates of cultures of strain P16 in the defined medium and in syncase medium that had similar enterotoxic activity were filtered through Sephadex-G50 columns and the fractions of effluent were examined for UV-light absorbence (fig. 3). The absorbence was much greater in material from "syncase " cultures than from cultures in the defined medium. Enterotoxic activity was detected in the void volume and in fractions between KAV 0.3 and 0.8 .

\section{Discussion}

Supernates from cultures of $E$. coli in " syncase " medium have proved unsatisfactory for the separation of enterotoxin because they contain contaminating materials from the growth medium. It seems possible that the use of the defined medium described here may alleviate this difficulty. Cultures of strain P16 in the defined medium gave yields of enterotoxic activity similar to those obtained in " syncase " medium, but with strain P99 the yield from the defined medium was somewhat less than from "syncase" medium.

The optimal concentration of glucose- $1.0 \%$ or $0.5 \%$-depends upon whether filtration is necessary in subsequent experimentation. Because the loss of enterotoxic activity is slight and the reduction in slime content is considerable when the glucose concentration is reduced, the lower concentration may be preferable for most purposes.

The observations that significant amounts of enterotoxin were produced only at high $p \mathrm{H}$ and that at high $p \mathrm{H}$ values the pathogenic strains grew relatively better in the defined medium than did the non-pathogens are of interest; they suggest that maintenance of a low $p \mathrm{H}$ in the gut may be important in maintaining a favourable balance between pathogenic and nonpathogenic strains of $E$. coli and in preventing enterotoxin-mediated scouring.

In view of the similarity in function (Moon, Whipp and Baetz, 1971; Evans et al., 1972) and in methods of production (Finkelstein et al., 1964; Kohler, 1968; Callahan and Richardson, 1973) of the enterotoxins of $E$. coli and Vibrio cholerae, it is likely that the medium and results described here may prove useful in work on cholera enterotoxin.

\section{SUMMARY}

A defined medium containing mineral salts, glucose and vitamins was developed in which large amounts of enterotoxin were produced by Escherichia coli strain P16 (serotype O9; K9) if the culture was well aerated during incubation for at least 48 hours and the $p \mathrm{H}$ was controlled to between $7 \cdot 4$ and $8 \cdot 1$.

After gel filtration of the supernates, the fractions with enterotoxic activity obtained from cultures in the defined medium contained considerably less ultra-violet-light absorbent material than did the corresponding fractions from cultures in "syncase" medium.

We are grateful to Mrs H. Steels, Mrs K. Martin and Mr M. Everett for their efficient technical assistance. 


\section{REFERENCES}

BYWATER, R. J. 1972. Dialysis and ultrafiltration of a heat-stable enterotoxin from Escherichia coli. J. med. Microbiol., 5, 337.

Callahan, L. T. and Richardson, S. H. 1973. Biochemistry of Vibrio cholerae virulence. III. Nutritional requirements for toxin production and the effects of $p \mathrm{H}$ on toxin elaboration in chemically defined media. Infect. Immun., 7, 567.

De, S. N. AND ChatterJeE, D. N. 1953. An experimental study on the mechanism of action of Vibrio cholerae on the intestinal mucous membrane. J. Path. Bact., 66, 559.

Evans, D. J., Chen, L. C., Curlin, G. T. and Evans, D. G. 1972. Stimulation of adenyl cyclase by Escherichia coli enterotoxin. Nature New Biol., Lond., 236, 137.

FinkelsteIn, R. A., Norris, H. T. AND DUTtA, N. K. 1964. Pathogenesis of experimental cholera in infant rabbits. 1. Observations on the intra-intestinal infection and experimental cholera produced with cell-free products. J. infect. Dis., 114, 203.

KOHLER, E. M. 1968. Enterotoxic activity of filtrates of Escherichia coli in young pigs. Am. J. vet. Res., 29, 2263.

LARIVIère, S. 1971. Physical and biological characterisation of Escherichia coli enterotoxin. $\mathrm{Ph} . \mathrm{D}$. Thesis, University of Guelph, Canada.

Moon, H. W., SORENSEN, D. K. AND SAUTTER, J. H. 1966. Escherichia coli infection of the ligated intestinal loop of the newborn pig. Am. J. vet. Res., 27, 1317.

Moon, H. W., WhIPP, S. C. AND BaETZ, A. L. 1971. Comparative effects of enterotoxins from Escherichia coli and Vibrio cholerae on rabbit and swine small intestine. Lab. Invest., 25, 133.

SMITH, H. W. AND GyLES, C. L. 1970. The effect of cell-free fluids prepared from cultures of human and animal enteropathogenic strains of Escherichia coli on ligated intestinal segments of rabbits and pigs. J. med. Microbiol., 3, 403.

Smith, H. W. AND Halls, S. 1967. Studies on Escherichia coli enterotoxin. J. Path. Bact., 93, 531 . 